\title{
Seeking health- and nutrition-related information on the Internet in a large population of French adults: results of the NutriNet-Santé study
}

\author{
Philippine Fassier $^{1 *}$, Anne-Sophie Chhim $^{1}$, Valentina A. Andreeva ${ }^{1}$, Serge Hercberg ${ }^{1,2}$, \\ Paule Latino-Martel ${ }^{1}$, Camille Pouchieu ${ }^{1}$ and Mathilde Touvier ${ }^{1}$ \\ ${ }^{1}$ Sorbonne Paris Cité Epidemiology and Statistics Research Center, Nutritional Epidemiology Research Team (EREN), Inserm \\ U1153, Inra U1125, Conservatoire National des Arts et Métiers (CNAM), University of Paris 13, F-93017 Bobigny, France \\ ${ }^{2}$ Public Health Department, Avicenne Hospital, F-93017 Bobigny, France
}

(Submitted 22 July 2015 - Final revision received 23 November 2015 - Accepted 8 March 2016 - First published online 15 April 2016)

\section{Abstract}

The Internet has become a major source of health and nutrition information. Little is known about the type of consulted websites (institutional $v$. non-institutional) and the tendency to discuss with a healthcare professional (HCP) the information found on the Internet. The aim of this cross-sectional study was to investigate health- and nutrition-related Internet use in a large French population-based study. Data were collected in 2013 using self-administered, web-based questionnaires from 42113 participants of the NutriNet-Santé study (mean age = 51.2 years, $76 \%$ women). Unconditional multivariate logistic regression analyses and $\chi^{2}$ tests were used for comparisons. In total, $85.1 \%$ of the subjects used the Internet to search for health and/or nutrition information, and $23.6 \%$ used the Internet to read or post messages on health/ nutrition forums. Only $16.0 \%$ discussed with a HCP the information found online. This proportion was lower in subjects with lower educational level (OR 0.77; $95 \%$ CI 0.72, 0.82) and lower computer skills (OR 0.70; $95 \%$ CI 0.65, 0.76). In total, 8038 health/nutrition websites were cited, with institutional websites representing only $12.9 \%$ of that number. Only one institutional website was present in the top 10. Older subjects (OR 1.49; $95 \%$ CI 1.28-1.74), those with lower educational level (OR 2.08; 95\% CI 1.75, 2.50) and lower nutritional knowledge (OR $1.33 ; 1.12,1.59)$ were more likely to cite non-institutional websites. This large population-based study showed that institutional websites were infrequently accessed and that a few participants discussed the information found online with their HCP. This particular trend was especially visible among individuals who were more vulnerable regarding misleading information. This supports the need to increase awareness of high-quality websites providing reliable health/nutrition information.

Key words: Health information: Information seeking: Internet: Nutrition information: Websites: General population

During the last decade, the Internet has become a major source of health and nutrition information ${ }^{(1,2)}$. More than $70 \%$ of European $^{(3,4)}$ and American citizens ${ }^{(5)}$ regularly use the Internet for health-related purposes. In a nationally representative US survey, when asked where they went for specific disease information (e.g. cancer), the majority of respondents reported going to the Internet first ${ }^{(6)}$. This phenomenon is occurring in parallel with the increased access to the Internet in developed countries. In France, $78 \%$ of the population had access to the Internet in $2012^{(2)}$, with the proportion being higher in young adults (96\% among those under 30 years) than in their older counterparts (62\% among those aged between 60 and 74 years and $23 \%$ among those aged $75+$ years).

Several studies have investigated the association between socio-demographic characteristics and the use of the Internet for health purposes, mainly in the $\mathrm{USA}^{(7-15)}$, and to a lesser extent in Europe ${ }^{(3,4,16-21)}$ and $\mathrm{Asia}^{(22,23)}$. These studies have consistently shown that women and people with higher socio-economic status were more likely to use the Internet for health purposes ${ }^{(3,16,18,21,23,24)}$. Results were more conflicting regarding the role of age ${ }^{(17,21-23)}$. A possible explanation is that most of the studies investigated general health-related use of the Internet, whereas only a few studies ${ }^{(1,3,5,8)}$ provided information on specific use such as searching for health-related information, reading or posting messages on health forums or using a coaching website. Besides, very few studies specifically investigated nutrition-related use of the Internet ${ }^{(13,16)}$.

The Internet is a valuable platform for the diffusion of reliable and valid health and nutrition information by public health institutions. However, the Internet also hosts a large number of websites and forums related to health and nutrition issues ${ }^{(25)}$ with content that is not always trustworthy or certified by experts and quality labels ${ }^{(26)}$. A few studies have provided information about the reliability of health/nutrition information

Abbreviation: HCP, healthcare professional.

* Corresponding author: P. Fassier, fax +3314838 8931, email p.fassier@eren.smbh.univ-paris13.fr 
found on the Internet ${ }^{(27-30)}$, and to our knowledge no previous study has quantified the proportion of institutional $v$. noninstitutional websites consulted by the public along with the respective socio-demographic profiles. In addition, limited information is available about whether individuals discuss the health information found on the Internet with a healthcare professional (HCP) $)^{(7,9,22,31-33)}$.

The aim of this study was to investigate health- and nutritionrelated Internet use (overall and specific use) in a large French population-based study. We also aimed to assess the proportion of institutional $v$. non-institutional consulted websites, as well as the tendency of subjects to discuss with a HCP the health and nutrition information they found on the Internet.

Our hypotheses were that the Internet would be largely used for health- and nutrition-related purposes, institutional websites would be less visited than non-institutional websites, a substantial proportion of subjects would not discuss with a HCP the information found on the Internet, and all these behaviours would depend on socio-demographic factors, nutritional knowledge and computer literacy.

\section{Methods}

\section{Subjects}

The ongoing NutriNet-Santé study is a large, web-based, general population cohort launched in France in May 2009 in order to evaluate the determinants of eating behaviour and the relationships between nutrition and chronic disease risk ${ }^{(34)}$. Participants are recruited by a vast multimedia campaign. Inclusion criteria are as follows: age $\geq 18$ years and access to the Internet. Registration and participation take place online using a dedicated and secure website (www.etude-nutrinet-sante.fr). Participants receive regular emails informing them about a new questionnaire to complete. The study website also provides general information on health and nutrition topics and on scientific publications related to the study. Participants receive no compensation for their participation in the study. This study was approved by the Institutional Review Board of the French Institute for Health and Medical Research (IRB Inserm no. 0000388FWA00005831) and the 'Commission Nationale de l'Informatique et des Libertés' (CNIL no. 908450 and no. 909216).

\section{Data collection}

Participants completed a baseline set of five self-administered, web-based questionnaires on socio-demographic and lifestyle characteristics, anthropometrics, dietary intake (3 24-h dietary records), physical activity and health status. Thereafter, these questionnaires are re-administered each year for information update purposes. All these instruments have been tested against traditional assessment methods (paper-and-pencil questionnaires or interview by a dietitian $)^{(35-37)}$. Data on sociodemographic characteristics included age, sex and educational level. The most current data were used for the present analysis.

One month after baseline, participants completed a questionnaire to assess their knowledge of official nutritional recommendations from the French National Nutrition and
Health Program (PNNS) regarding the following food groups: fruits and vegetables, dairy products, starchy foods, meat, fish and eggs, and seafood.

In October 2013, all subjects were sent a computer literacy questionnaire, to be completed online ${ }^{(38)}$, which aimed to gather information on the use of the Internet for health and/or nutritional purposes. Specifically, participants were asked whether they used the Internet to search for health/nutrition information, whether they discussed this information with a HCP, whether they bought dietary supplements online, whether they read/ posted messages on health/nutrition forums, whether they used health/nutrition coaching websites and whether they used the Internet to find or to communicate with a HCP. Subjects were also asked to report the name of websites they most frequently used to find health/nutrition information. This questionnaire was not mandatory, and no reminder was sent to non-responders.

\section{Statistical analyses}

Multivariate unconditional logistic regression analyses were used to assess the associations between specific health- and nutrition-related use of the Internet and socio-demographic characteristics (sex: female $v$. male, age: $>50$ years $v$. $\leq 50$ years, educational level: $>12$ years $v . \leq 12$ years of schooling, which corresponds to the French Baccalaureate), self-rated computer skills (experienced/expert $v$. novice/inexperienced) and level of knowledge of nutritional recommendations $(\geq 3 v .<3$ known recommendations).

The websites cited by participants were classified into two categories: 'institutional' or official (run by public research institutes, governmental institutions, the Ministry of Health, etc.) and 'non-institutional' websites. The top 10 most-cited websites were computed overall and separately for institutional and non-institutional websites.

The proportion of non-institutional websites cited by participants was compared across categories of socio-demographic characteristics, self-rated computer skills and level of nutritional recommendation knowledge using $\chi^{2}$ tests (univariate model) and multivariate unconditional logistic regression models.

$P<0.05$ was considered to be statistically significant. All tests were two-sided. Analyses were carried out using SAS version 9.3 (SAS Institute Inc.).

\section{Results}

Of the 123984 participants included in the NutriNet-Santé study between May 2009 and October 2013, 43028 individuals (34.7\%) returned this optional questionnaire on computer skills and Internet use. Among them, 42113 subjects (97.9\%) had available data on all studied covariates, and were thus included in the present study. Characteristics of the study population are presented in Table 1 . In all, $76.0 \%$ of the participants were women, $56.4 \%$ were aged 50 years and older, 36.9\% had completed 12 years of schooling or less, $23 \cdot 8 \%$ considered themselves as novice/inexperienced in computer use and $29 \cdot 2 \%$ knew fewer than three official nutritional recommendations. The proportions of subjects according to sex, age and educational level categories are presented in the online Supplementary Table S1 and 
Table 1. Baseline characteristics of the study population, NutriNet-Santé study, France, 2013

(Numbers and percentages; $n$ 42113)

\begin{tabular}{|c|c|c|}
\hline & $n$ & $\%$ \\
\hline \multicolumn{3}{|l|}{ Sex } \\
\hline Female & 32026 & $76 \cdot 0$ \\
\hline Male & 10087 & $24 \cdot 0$ \\
\hline \multicolumn{3}{|l|}{ Age } \\
\hline$\leq 50$ years & 18375 & 43.6 \\
\hline$>50$ years & 23738 & $56 \cdot 4$ \\
\hline \multicolumn{3}{|l|}{ Educational level } \\
\hline$\leq 12$ years of schooling & 15529 & 36.9 \\
\hline$>12$ years of schooling & 26584 & 63.1 \\
\hline \multicolumn{3}{|c|}{ Self-rated level of computer skills } \\
\hline Novice/inexperienced & 10011 & $23 \cdot 8$ \\
\hline Experienced/expert & 32102 & $76 \cdot 2$ \\
\hline \multicolumn{3}{|c|}{ Number of known nutritional recommendations ${ }^{*}$} \\
\hline$<3$ & 12284 & 29.2 \\
\hline $3-5$ & 29829 & $70 \cdot 8$ \\
\hline
\end{tabular}

compared between the French adult population (National census $\left.2014^{(39)}\right)$, the overall NutriNet-Santé cohort and the present study population.

Results regarding specific usage of the Internet for health and nutrition purposes and the correlates are presented in Table 2. A large proportion of subjects used the Internet to search for health and/or nutrition information $(85.1 \%)$. This proportion was higher in women (OR 1.55; $95 \%$ CI 1.46, 1.65), in older subjects (OR 1.42; $95 \%$ CI 1.34, 1.50) and in those with lower educational level (OR 1.14; 95\% CI 1.08, 1.2), and the proportion was lower in participants with lower computer skills (OR $0.79 ; 95 \%$ CI 0.74, 0.84) and in those with lower nutritional knowledge (OR 0.83; 95\% CI 0.78, 0.88).

About a quarter of the study population (23.6\%) used the Internet to read or post messages on health/nutrition forums. This proportion was higher in women (OR 1.18 ; $95 \%$ CI $1 \cdot 12$, 1.25) and in subjects with lower educational level (OR 1.08; $95 \%$ CI $1.02,1.12)$, whereas the proportion was lower in older subjects (OR $0.82 ; 95 \%$ CI $0.78,0.86)$ and in those with lower computer skills (OR 0.68; 95\% CI 0.64, 0.72).

About $12.0 \%$ of the subjects used the Internet to purchase dietary supplements online, $41.5 \%$ used the Internet to find a HCP and $9.5 \%$ to communicate with a HCP. The use of a health/nutrition 'coaching' website was relatively limited (7.6\% of the subjects).

Only $16.0 \%$ discussed the information obtained from the web with a HCP. This proportion was even lower in subjects with lower educational level (OR 0.77; $95 \%$ CI 0.72, 0.82) and lower computer skills (OR $0.70 ; 95 \%$ CI $0 \cdot 65,0.76$ )

The 10 most-cited health/nutrition websites are presented in Table 3. In all, 8038 names of websites were cited by 7237 participants (several responses possible per subject). By far, the most frequently cited website was Doctissimo ( $45.5 \%$ of the responses), a French, non-institutional website dedicated to general health. Institutional websites only represented $12.9 \%$ of the responses. Among the top 10 websites, the only institutional website was www.MangerBouger.fr, which is the official website of the PNNS run by the Ministry of Health. However, it only represented $1.4 \%$ of the responses.

As shown in Table 4, older subjects (OR 1.49; $95 \%$ CI 1.28, $1 \cdot 74$ ), those with lower educational level (OR 2.08; $95 \%$ CI 1.75 , $2 \cdot 50$ ) and those with lower nutritional knowledge (OR 1.33; $95 \%$ CI $1.12,1.59)$ were more likely to cite non-institutional websites. Sex was not associated with the type (institutional $v$. non-institutional) of consulted websites $(P=0 \cdot 5)$.

\section{Discussion}

In this large, population-based study, a substantial proportion of subjects declared using the Internet for health and/or nutrition purposes, with notable socio-demographic disparities. A relatively small proportion of participants discussed the information obtained from the web with a HCP. Institutional websites represented only a small proportion of the $>8000$ cited websites, with only one institutional website being in the top 10 . It should be noted that subjects with a lower educational level were more likely to search for health/nutrition information on the Internet and to read/post messages in dedicated forums, but were less inclined to discuss that information with a HCP or to consult institutional websites.

In all, $85 \%$ of the subjects in this study declared using the Internet to search for information on health and/or nutrition. This proportion is higher than the one reported by the 2011 survey on Internet-based health information seeking in a representative sample of the French population $(46 \%)^{(40)}$. In the USA, the corresponding proportion was $80 \%$ in a 2010 representative survey ${ }^{(5)}$. However, in those studies, the questions only referred to health and not to health and nutrition. To our knowledge, the few studies that investigated the use of the Internet to search for nutrition information have reported a prevalence of about $43 \%$ in the $\mathrm{USA}^{(13)}$ and $41 \%$ in $\operatorname{Italy}^{(16)}$.

In line with previously published data in France ${ }^{(2,18,21)}$ and $\operatorname{abroad}^{(7,8,16,19,41-43)}$, women were more likely to use the Internet for health and nutrition purposes. Results regarding age trends are more contrasted in the literature, with some studies indicating higher Internet use among older subjects ${ }^{(15,18)}$, while others reported the contrary ${ }^{(3,14,23)}$. These inconsistencies could partly be explained by the fact that most studies evaluated health-related Internet use overall. Indeed, in our study, the associations between nutrition/health-related Internet use and age and educational level varied according to the purpose of usage: older participants were more likely to use the Internet to purchase dietary supplements online, whereas younger subjects were more inclined to read or post messages on heath/nutrition forums. Next, educational level was correlated with higher health-related Internet use in previous studies $^{(7,18,21,22,24,41)}$. However, our results suggest that the association between educational level and health-related Internet use may depend on the specific use. Indeed, people with lower educational level were more likely to search for health/nutrition information on the Internet and to visit health forums, but were less likely to use the Internet to communicate with or find a HCP, compared with their counterparts with a higher educational level. 
Table 2. Multivariate associations between health- and nutrition-related use of the Internet and sex, age, education, self-evaluated computer skills and knowledge of nutritional recommendations, NutriNet-Santé study, France, 2013

(Numbers, percentages, odds ratios and $95 \%$ confidence intervals; $n$ 42113)*

\begin{tabular}{|c|c|c|c|c|c|}
\hline & $n$ & $\%$ & OR & $95 \% \mathrm{Cl}$ & $P$ \\
\hline 1. Searching for health and/or nutrition information (yes) & 35852 & $85 \cdot 1$ & & & \\
\hline Sex (female $v$. male) & & & 1.55 & $1.46,1.65$ & $<0.0001$ \\
\hline Age (>50 years $v . \leq 50$ years) & & & 1.42 & $1.34,1.50$ & $<0.0001$ \\
\hline Educational level ( $\leq 12$ years of schooling $v .>12$ years) & & & $1 \cdot 14$ & $1 \cdot 08,1 \cdot 2$ & $<0.0001$ \\
\hline Level of computer skills (novice/inexperienced $v$. experienced/expert) & & & 0.79 & $0.74,0.84$ & $<0.0001$ \\
\hline Knowledge of nutritional recommendations ( $<3 v . \geq 3$ known recommendations) $\dagger$ & & & 0.83 & $0.78,0.88$ & $<0.0001$ \\
\hline 2. Purchasing dietary supplements online (yes) & 4933 & $11 \cdot 7$ & & & \\
\hline Sex (female $v$. male) & & & $1 \cdot 28$ & $1 \cdot 19,1.38$ & $<0.0001$ \\
\hline Age (>50 years $v . \leq 50$ years) & & & 1.51 & $1.42,1.61$ & $<0.0001$ \\
\hline Educational level ( $\leq 12$ years of schooling $v .>12$ years) & & & 1.08 & $1.01,1.15$ & 0.01 \\
\hline Level of computer skills (novice/inexperienced $v$. experienced/expert) & & & 0.78 & $0.72,0.84$ & $<0.0001$ \\
\hline Knowledge of nutritional recommendations ( $<3 v . \geq 3$ known recommendations) $\dagger$ & & & $1 \cdot 15$ & $1.08,1.22$ & $<0.0001$ \\
\hline 3. Reading or posting messages on health/nutrition forums (yes) & 9932 & $23 \cdot 6$ & & & \\
\hline Sex (female $v$. male) & & & $1 \cdot 18$ & $1 \cdot 12,1 \cdot 25$ & $<0.0001$ \\
\hline Age ( $>50$ years $v . \leq 50$ years) & & & 0.82 & $0.78,0.86$ & $<0.0001$ \\
\hline Educational level ( $\leq 12$ years of schooling $v .>12$ years) & & & 1.08 & $1.02,1.12$ & 0.003 \\
\hline Level of computer skills (novice/inexperienced $v$. experienced/expert) & & & 0.68 & $0.64,0.72$ & $<0.0001$ \\
\hline Knowledge of nutritional recommendations ( $<3 v . \geq 3$ known recommendations) $\dagger$ & & & 0.99 & $0.93,1.04$ & 0.6 \\
\hline 4. Using a health/nutrition 'coaching' website (yes) & 3215 & $7 \cdot 6$ & & & \\
\hline Sex (female $v$. male) & & & 1.37 & $1 \cdot 25,1.50$ & $<0.0001$ \\
\hline Age (>50 years $v . \leq 50$ years) & & & $0 \cdot 78$ & $0.72,0.84$ & $<0.0001$ \\
\hline Educational level ( $\leq 12$ years of schooling $v .>12$ years) & & & $1 \cdot 32$ & $1 \cdot 22,1.41$ & $<0.0001$ \\
\hline Level of computer skills (novice/inexperienced $v$. experienced/expert) & & & 0.63 & $0.57,0.69$ & $<0.0001$ \\
\hline Knowledge of nutritional recommendations ( $<3 \mathrm{v} . \geq 3$ known recommendations) $\dagger$ & & & 0.88 & $0.81,0.95$ & 0.002 \\
\hline 5. Communicating (by email or Internet) with a HCP (yes) & 3987 & $9 \cdot 5$ & & & \\
\hline Sex (female $v$. male) & & & 0.85 & $0.79,0.92$ & $<0.0001$ \\
\hline Age ( $>50$ years $v . \leq 50$ years) & & & $1 \cdot 11$ & $1.04,1.19$ & 0.003 \\
\hline Educational level ( $\leq 12$ years of schooling $v .>12$ years) & & & 0.71 & $0.67,0.77$ & $<0.0001$ \\
\hline Level of computer skills (novice/inexperienced $v$. experienced/expert) & & & 0.63 & $0.57,0.68$ & $<0.0001$ \\
\hline Knowledge of nutritional recommendations ( $<3 v . \geq 3$ known recommendations) $\dagger$ & & & 0.98 & $0.91,1.05$ & 0.6 \\
\hline 6. Finding a HCP (yes) & 17478 & 41.5 & & & \\
\hline Sex (female $v$. male) & & & 1.40 & $1.33,1.47$ & $<0.0001$ \\
\hline Age ( $>50$ years $v . \leq 50$ years) & & & 0.57 & $0.54,0.59$ & $<0.0001$ \\
\hline Educational level ( $\leq 12$ years of schooling $v .>12$ years) & & & 0.87 & $0.83,0.91$ & $<0.0001$ \\
\hline Level of computer skills (novice/inexperienced $v$. experienced/expert) & & & 0.63 & $0.60,0.66$ & $<0.0001$ \\
\hline Knowledge of nutritional recommendations ( $<3 v . \geq 3$ known recommendations) $\dagger$ & & & 0.97 & $0.93,1.02$ & 0.3 \\
\hline 7. Did you discuss the information obtained from the web with a HCP? $\ddagger$ (yes) & 5898 & $16 \cdot 0$ & & & \\
\hline Sex (female $v$. male) & & & 1.00 & $0.93,1.07$ & 0.9 \\
\hline Age $(>50$ years $v . \leq 50$ years) & & & 1.05 & $0.99,1.11$ & $0 \cdot 1$ \\
\hline Educational level ( $\leq 12$ years of schooling $v .>12$ years) & & & 0.77 & $0.72,0.82$ & $<0.0001$ \\
\hline Level of computer skills (novice/inexperienced $v$. experienced/expert) & & & $0 \cdot 70$ & $0.65,0.76$ & $<0.0001$ \\
\hline Knowledge of nutritional recommendations ( $<3 \mathrm{v} . \geq 3$ known recommendations) $\dagger$ & & & 0.95 & $0.90,1.02$ & $0 \cdot 2$ \\
\hline
\end{tabular}

HCP, healthcare professional.

* From unconditional logistic regression models adjusted for sex, age, educational level, self-rated level of computer skills and knowledge of nutritional recommendations.

† Official recommendations from the French National Nutrition and Health Program (PNNS). (five recommendations assessed).

$\ddagger$ Only completed by participants who answered 'yes' to at least one of the questions, no. 1, 2, 3 or 4 ( $n 36988$ ).

Although the Internet could be strategically used to relay validated health and nutrition information to help with disease prevention $^{(21)}$, our study showed that institutional (official) websites only represented a small proportion (12.9\%) of all cited health/nutrition websites. The first cited institutional website was the official website of the PNNS; it only represented $1.4 \%$ of the responses. This is worrisome because the majority of people trust the information obtained on the Internet $^{(21)}$, where the quality and reliability of health information of non-institutional websites may vary substantially $^{(27,30)}$. This was illustrated by a recent UK study, which showed that correct paediatric information was only provided by four out of ten consulted websites ${ }^{(30)}$.

Another important concern is the fact that people with lower educational levels and lower nutritional knowledge (i.e. potentially more vulnerable individuals when confronted with misleading information) were more likely to refer to noninstitutional websites. A recent survey ${ }^{(44)}$ showed that skilled web users effectively filtered information according to search intentions and data sources, whereas less-skilled users were easily distracted by unrelated information.

In contrast, young adults more frequently cited institutional websites than did their older counterparts. This result is encouraging, as the young represent the new generation and as they also are the ones with increased access to the Internet ${ }^{(2)}$.

In France as in other countries, strategies should be implemented to develop and promote the use of reliable institutional websites via different tactics such as search marketing, digital marketing, Search Engine Optimization or social media marketing. Besides, targeting within those communication 
Table 3. Top 10 of the health- and/or nutrition-related websites cited by the participants of the NutriNet-Santé study, France, 2013 ( $n 8038$ cited websites)*

\begin{tabular}{|c|c|c|c|c|c|c|c|c|}
\hline \multicolumn{3}{|c|}{ Top 10 - all answers ( $n$ 8038) } & \multicolumn{3}{|c|}{ Top 10 - institutional websites ( $n$ 1033) } & \multicolumn{3}{|c|}{ Top 10 - non-institutional websites ( $n$ 7005) } \\
\hline Websites & No. of citations & $\%$ & Websites & No. of citations & $\%$ & Websites & No. of citations & $\%$ \\
\hline Doctissimo & 3654 & 45.5 & MangerBouger & 113 & $10 \cdot 9$ & Doctissimo & 3654 & $52 \cdot 2$ \\
\hline Passeport Santé & 470 & 5.9 & PubMed & 94 & $9 \cdot 1$ & Passeport Santé & 470 & $6 \cdot 7$ \\
\hline Allo Docteur & 269 & 3.4 & Vidal & 90 & 8.7 & Allo Docteur & 269 & 3.8 \\
\hline e-santé.fr & 227 & $2 \cdot 8$ & Ameli & 86 & $8 \cdot 3$ & e-santé.fr & 227 & $3 \cdot 2$ \\
\hline Wikipédia & 218 & $2 \cdot 7$ & HAS & 72 & $7 \cdot 0$ & Wikipédia & 218 & $3 \cdot 1$ \\
\hline LaNutrition.fr & 195 & $2 \cdot 4$ & ANSES & 63 & $6 \cdot 1$ & LaNutrition.fr & 195 & $2 \cdot 8$ \\
\hline Medisite & 191 & $2 \cdot 4$ & INPES & 56 & 5.4 & Medisite & 191 & $2 \cdot 7$ \\
\hline Santé Nature Innovation & 143 & 1.8 & NutriNet-Santé & 42 & $4 \cdot 1$ & Santé Nature Innovation & 143 & $2 \cdot 0$ \\
\hline MangerBouger & 113 & 1.4 & AFDN & 30 & $2 \cdot 9$ & EurekaSanté & 98 & 1.4 \\
\hline EurekaSanté & 98 & 1.2 & ANSM & 29 & 2.8 & Weight Watchers & 84 & 1.2 \\
\hline Total of top 10 & 5578 & 69.5 & Total of top 10 & 675 & $65 \cdot 3$ & Total of top 10 & 5549 & $79 \cdot 1$ \\
\hline
\end{tabular}

HAS, Haute Autorité de Santé; ANSES, Agence Nationale de Sécurité Sanitaire de l'Alimentation, de l'Environnement et du Travail; INPES, Institut National de Prévention et d'Education pour la Santé; AFDN, Association Française des Diététiciens Nutritionnistes; ANSM, Agence Nationale de Sécurité du Médicament et des produits de santé.

* Cited by 7237 subjects who declared a specific health/nutrition website. Several possible responses per subject.

Table 4. Multivariate associations between the type of cited websites (non-institutional $v$. institutional) and sex, age, education, self-evaluated computer skills and knowledge of nutritional recommendations, NutriNet-Santé study, France, 2013 ( $n 8038$ cited websites)

(Numbers, percentages; odds ratios and $95 \%$ confidence intervals)

\begin{tabular}{|c|c|c|c|c|c|c|c|c|}
\hline & \multicolumn{4}{|c|}{ Citations of health and/or nutrition websites } & & & & \\
\hline & \multicolumn{2}{|c|}{ Non-institutional } & \multicolumn{2}{|c|}{ Institutional } & \multicolumn{2}{|c|}{ Univariate model } & \multicolumn{2}{|c|}{ Multivariate model } \\
\hline & $n$ & $\%$ & $n$ & $\%$ & $P^{*}$ & OR & $95 \% \mathrm{Cl}$ & $P \dagger$ \\
\hline Overall & 7005 & $87 \cdot 1$ & 1033 & $12 \cdot 9$ & & & & \\
\hline Sex & & & & & 0.9 & & & 0.5 \\
\hline Male & 1364 & $87 \cdot 2$ & 200 & $12 \cdot 8$ & & 1 & & \\
\hline Female & 5641 & $87 \cdot 1$ & 833 & $12 \cdot 9$ & & 1.06 & $0.88,1.28$ & \\
\hline Age & & & & & $<0.0001$ & & & $<0.0001$ \\
\hline$\leq 50$ years & 3154 & 83.5 & 623 & $16 \cdot 5$ & & 1 & & \\
\hline$>50$ years & 3851 & 90.4 & 410 & 9.6 & & 1.49 & $1.28,1.74$ & \\
\hline Educational level & & & & & $<0.0001$ & & & $<0.0001$ \\
\hline$\leq 12$ years of schooling & 2776 & $92 \cdot 8$ & 214 & $7 \cdot 2$ & & 2.08 & $1.75,2.50$ & \\
\hline$>12$ years of schooling & 4229 & 83.8 & 819 & $16 \cdot 2$ & & 1 & & \\
\hline Self-rated level of computer skills & & & & & 0.0010 & & & 0.2 \\
\hline Novice/inexperienced & 1402 & $89 \cdot 6$ & 162 & $10 \cdot 4$ & & $1 \cdot 14$ & $0.93,1.37$ & \\
\hline Experienced/expert & 5603 & $86 \cdot 6$ & 871 & 13.5 & & 1 & & \\
\hline Number of known nutritional recommendations $\ddagger$ & & & & & 0.0002 & & & 0.0008 \\
\hline$<3$ & 1902 & 89.5 & 224 & 10.5 & & 1.33 & $1.12,1.59$ & \\
\hline$\geq 3$ & 5103 & $86 \cdot 3$ & 809 & 13.7 & & 1 & & \\
\hline
\end{tabular}

* $P$ value for the comparison of the proportion of institutional/non-institutional websites cited across categories of participants, by $\chi^{2}$ test.

† $P$ value from multivariate unconditional logistic regression models adjusted for sex, age, educational level, self-rated level of computer skills and knowledge of nutritional recommendations. The probability to cite non-institutional websites (rather than institutional websites) is modelled.

¥ Official recommendations from the French National Nutrition and Health Program (PNNS) (five recommendations assessed).

channels could contribute to address some of the sociodemographic and economic discrepancies observed in this study. In France, the National Institute for Prevention and Health Education (INPES) has provided many reliable information resources on the Internet (including social networks) during the last decade ${ }^{(21)}$. Existing institutional websites should be made known, and new ones should be created, where the provided health information is clearly referenced and controlled. The use of quality labels (such as the 'Health On the Net' label ${ }^{(33)}$ ) should be generalised. This process is already in place in the USA and Australia ${ }^{(45,46)}$.

In our study, only $16 \%$ of the participants discussed health/ nutrition information found on the web with a HCP. A similar proportion (17\%) was observed in Japan ${ }^{(22)}$, about $35^{(7)}$ and $50 \%{ }^{(9,32)}$ were reported in US studies and $73 \%$ in Saudi Arabia ${ }^{(31)}$. Renahy et $a l .{ }^{(18)}$ showed that people who were more likely to search for health information on the Internet were those who would appreciate more attention from their physician and who were more inclined to think that physicians did not tell them everything about their health. AlGhamdi et al. ${ }^{(31)}$ showed that some of the reasons for searching for health information on the Internet were not getting enough information from the physician (59\%) and not trusting the information given by the physician ( $28 \%$ ).

Subjects with lower educational level and lower computer skills were even less inclined to discuss with a HCP the 
information obtained on the Internet. Similar results have been reported by Seçkin et al. ${ }^{(32)}$ regarding educational level. Those subjects were also the ones more likely to consult non-institutional websites in our study.

Strengths of this study pertain to the use of a large population-based e-cohort and detailed information on healthand nutrition-related use of the Internet, including type of consulted websites (institutional or not) and purpose (information search, participation in web forums, use of coaching websites, etc.), and data on discussing the information found on the Internet with a HCP.

Several limitations should be acknowledged. First, caution is needed in extrapolating our results to the general French population, as the NutriNet-Santé study involved a sample of volunteers who accepted to participate in a survey on nutrition and health. As shown in Supplementary Table S1 and in previous publications ${ }^{(39,47)}$, the NutriNet-Santé study included more women and more individuals with higher educational level, as compared with national estimates. Besides, the response rate to this specific non-mandatory questionnaire was $35 \%$. Non-response to this questionnaire did not alter the enrolment status of the participants. Compared with non-responders for this specific questionnaire, responders were more likely to be men, older and better educated, but except for age these differences were small. As non-institutional websites are more frequently cited by subjects with lower educational level and lower nutritional knowledge, we can hypothesise that the proportion of consulted institutional websites is even lower in the French general population than the one observed in this study (which is already very low).

Second, even if participants of this observational nutrition cohort do not receive explicit nutritional advice, the link to the PNNS website (www.mangerbouger.fr) is provided on the NutriNet-Santé website. This may have artificially increased the citation of this website. However, despite this potential bias, www.mangerbouger.fr was only cited by $1.4 \%$ of the responses in this study, and we can hypothesise that this proportion is even lower in the general population.

Third, the questions asked to the participants included nutrition and health together; thus, it was not possible to disentangle these two points in this data set.

Finally, the available data did not allow us to find out whether the subjects searched for a particular website to then search for that information there, or if they searched for health terms via a search engine and simply clicked on the result. In the first case (a priori selection of websites by the individual), the question raised pertains to consumers' understanding of what constitutes reliable health information. In the second case (use of search engines), our results suggest that institutional websites are not being found easily by citizens in the top search results, which underlines the issue of how institutions build and market their websites.

In conclusion, this large study provided an important insight into the use of the Internet for health and/or nutrition purposes. Key findings were that institutional (official) websites with reliable and valid information constituted only a small portion of all consulted websites, and that relatively few participants discussed with their HCP the information found on the Internet.
Our results also highlighted the fact that individuals who were more vulnerable regarding potentially misleading health/nutrition information (e.g. subjects with lower educational level) were more likely to use non-institutional websites and less likely to confront the information found on the Internet with a HCP. These results support the need to develop, maintain and increase awareness of user-friendly, well-referenced websites and web-based tools (e.g. Facebook pages, videos), run by public health stakeholders, in order to improve the access to high-quality health- and nutrition-related information at the population level, including individuals with low educational level and computer skills.

\section{Acknowledgements}

The authors thank Younes Esseddik, Paul Flanzy, Mohand Ait Oufella, Yasmina Chelghoum and Than Duong Van (computer scientists); Dr Nathalie Pecollo (operational coordinator); and Nathalie Arnault, Véronique Gourlet, Dr Fabien Szabo, Charlie Ménard, Laurent Bourhis and Stephen Besseau (statisticians) for their technical contribution to the NutriNet-Santé study.

P. F. was funded by a PhD grant from the Cancéropôle Ile-deFrance (public funding from the Paris region). C. P. was funded by a PhD grant from the French Ministry of Research and Higher Education (no. 11/ED G/UREN/2011). The NutriNet-Santé study was supported by the following public institutions: Ministère de la Santé, Institut de Veille Sanitaire, Institut National de la Prévention et de l'Education pour la Santé, Fondation pour la Recherche Médicale, Institut National de la Santé et de la Recherche Médicale, Institut National de la Recherche Agronomique, Conservatoire National des Arts et Métiers and Université Paris 13.

Contributors P. F. and M. T. designed the study; P. F., C. P., A. S. C., M. T. and S. H. conducted the study; P. F., A. S. C. and C. P. analysed the data; P. F. led the writing; M. T. supervised the study; P. F., A. S. C., V. A. A., S. H., P. L. M., C. P. and M. T. contributed to data interpretation and revised each draft for important intellectual content; M. T. had primary responsibility for the final content. All the authors read and approved the final version of the manuscript.

The authors declare that there are no competing interests.

\section{Supplementary material}

For supplementary material/s referred to in this article, please visit http://dx.doi.org/doi:10.1017/S0007114516001355

\section{References}

1. Baker L, Wagner TH, Singer S, et al. (2003) Use of the Internet and e-mail for health care information: results from a national survey. JAMA 289, 2400-2406.

2. National Institute of Statistics and Economic Studies (INSEE) (2015) Internet increasingly popular, web users increasingly mobile. http://www.insee.fr/fr/ffc/ipweb/ip1452/ip1452.pdf (accessed January 2015). 
3. Andreassen HK, Bujnowska-Fedak MM, Chronaki CE, et al. (2007) European citizens' use of E-health services: a study of seven countries. BMC Public Health 7, 53.

4. Nolke L, Mensing M, Kramer A, et al. (2015) Sociodemographic and health-(care-)related characteristics of online health information seekers: a cross-sectional German study. BMC Public Health 15, 31.

5. Fox S (2011) The social life of health information, 2011. http:// pewinternet.org/Reports/2011/Social-Life-of-Health-Info.aspx (accessed January 2015).

6. Hesse BW, Moser RP \& Rutten LJ (2010) Surveys of physicians and electronic health information. N Engl J Med 362, 859-860.

7. Chung JE (2013) Patient-provider discussion of online health information: results from the 2007 Health Information National Trends Survey (HINTS). J Health Commun 18, 627-648.

8. Cohen RA \& Stussman B (2010) Health information technology use among men and women aged 18-64: early release of estimates from the National Health Interview Survey, January-June 2009. http://www.cdc.gov/nchs/data/ hestat/healthinfo2009/healthinfo2009.pdf (accessed January 2015).

9. Fox S (2015) Health Online 2013. http://www.pewinternet. org/files/old-media//Files/Reports/PIP_HealthOnline.pdf (accessed January 2015).

10. Koch-Weser S, Bradshaw YS, Gualtieri L, et al. (2010) The Internet as a health information source: findings from the 2007 Health Information National Trends Survey and implications for health communication. J Health Commun 15, Suppl. 3 279-293.

11. Lee YJ, Boden-Albala B, Larson E, et al. (2014) Online health information seeking behaviors of Hispanics in New York City: a community-based cross-sectional study. J Med Internet Res 16, e176.

12. Lustria ML, Smith SA \& Hinnant CC (2011) Exploring digital divides: an examination of eHealth technology use in health information seeking, communication and personal health information management in the USA. Health Informatics J 17, 224-243.

13. McCully SN, Don BP \& Updegraff JA (2013) Using the Internet to help with diet, weight, and physical activity: results from the Health Information National Trends Survey (HINTS). J Med Internet Res 15, e148.

14. Ybarra ML \& Suman M (2006) Help seeking behavior and the Internet: a national survey. Int J Med Inform 75, 29-41.

15. Zulman DM, Kirch M, Zheng K, et al. (2011) Trust in the internet as a health resource among older adults: analysis of data from a nationally representative survey. J Med Internet Res 13, e19.

16. Bianco A, Zucco R, Nobile CG, et al. (2013) Parents seeking health-related information on the Internet: crosssectional study. J Med Internet Res 15, e204.

17. Renahy E, Parizot I \& Chauvin P (2008) Health information seeking on the Internet: a double divide? Results from a representative survey in the Paris metropolitan area, France, 2005-2006. BMC Public Health 8, 69.

18. Renahy E, Parizot I \& Chauvin P (2010) Determinants of the frequency of online health information seeking: results of a web-based survey conducted in France in 2007. Inform Health Soc Care 35, 25-39.

19. Siliquini R, Ceruti M, Lovato E, et al. (2011) Surfing the internet for health information: an Italian survey on use and population choices. BMC Med Inform Decis Mak 11, 21.

20. Terlutter R, Bidmon S \& Rottl J (2014) Who uses physicianrating websites? Differences in sociodemographic variables, psychographic variables, and health status of users and nonusers of physician-rating websites. J Med Internet Res $\mathbf{1 6}$, e97.

21. Beck F, Richard JB, Nguyen-Thanh V, et al. (2014) Use of the internet as a health information resource among French young adults: results from a nationally representative survey. J Med Internet Res 16, e128.

22. Takahashi Y, Ohura T, Ishizaki T, et al. (2011) Internet use for health-related information via personal computers and cell phones in Japan: a cross-sectional population-based survey. J Med Internet Res 13, e110.

23. Wang MP, Viswanath K, Lam TH, et al. (2013) Social determinants of health information seeking among Chinese adults in Hong Kong. PLOS ONE 8, e73049.

24. Lee K, Hoti K, Hughes JD, et al. (2014) Dr Google and the consumer: a qualitative study exploring the navigational needs and online health information-seeking behaviors of consumers with chronic health conditions. J Med Internet Res 16. e 262

25. Wantland DJ, Portillo CJ, Holzemer WL, et al. (2004) The effectiveness of Web-based vs. non-Web-based interventions: a meta-analysis of behavioral change outcomes. I Med Internet Res $\mathbf{6}$, e40.

26. Nabarette H, Romaneix F, Boyer C, et al. (2009) [Certification of health-related websites in France]. Presse Med $\mathbf{3 8}$, $1476-1483$

27. Lawrentschuk N, Abouassaly R, Hackett N, et al. (2009) Health information quality on the internet in urological oncology: a multilingual longitudinal evaluation. Urology 74, 1058-1063.

28. Ream E, Blows E, Scanlon K, et al. (2009) An investigation of the quality of breast cancer information provided on the internet by voluntary organisations in Great Britain. Patient Educ Couns 76, 10-15.

29. Reavley NJ \& Jorm AF (2011) The quality of mental disorder information websites: a review. Patient Educ Couns 85 , e16-e25.

30. Scullard P, Peacock C \& Davies P (2010) Googling children's health: reliability of medical advice on the internet. Arch Dis Child 95, 580-582.

31. AlGhamdi KM \& Moussa NA (2012) Internet use by the public to search for health-related information. Int J Med Inform $\mathbf{8 1}$, 363-373.

32. Seçkin G (2014) Health information on the web and consumers' perspectives on health professionals' responses to information exchange. Med $20 \mathbf{3}$, e4.

33. Fox S (2015) The Health On the Net. Winter 2004-2005. http://www.hon.ch/Survey/Survey2005/res.html (accessed January 2015).

34. Hercberg S, Castetbon K, Czernichow S, et al. (2010) The Nutrinet-Sante Study: a web-based prospective study on the relationship between nutrition and health and determinants of dietary patterns and nutritional status. BMC Public Health 10, 242.

35. Touvier M, Mejean C, Kesse-Guyot E, et al. (2010) Comparison between web-based and paper versions of a self-administered anthropometric questionnaire. Eur J Epidemiol 25, 287-296.

36. Touvier M, Kesse-Guyot E, Mejean C, et al. (2011) Comparison between an interactive web-based self-administered $24 \mathrm{~h}$ dietary record and an interview by a dietitian for large-scale epidemiological studies. Br J Nutr 105, 1055-1064.

37. Vergnaud AC, Touvier M, Mejean C, et al. (2011) Agreement between web-based and paper versions of a sociodemographic questionnaire in the NutriNet-Sante study. Int $J$ Public Health 56, 407-417.

38. Pouchieu C, Mejean C, Andreeva VA, et al. (2015) How computer literacy and socioeconomic status affect attitudes 
toward a Web-based cohort: results from the NutriNetSante study. J Med Internet Res 17, e34.

39. Institut National de la Statistique et des Etudes Economiques (INSEE) (2014) Population by sex and age on 1st January, France except Mayotte. http://www.insee.fr/en/themes/ (accessed January 2015).

40. National Institute of Statistics and Economic Studies (INSEE) (2015) Two out of three households have Internet access at home. http://www.insee.fr/fr/ffc/ipweb/ip1340/ip1340.pdf (accessed January 2015).

41. Anderson-Bill ES, Winett RA \& Wojcik JR (2011) Social cognitive determinants of nutrition and physical activity among web-health users enrolling in an online intervention: the influence of social support, self-efficacy, outcome expectations, and self-regulation. J Med Internet Res 13, e28.

42. Kummervold PE, Chronaki CE, Lausen B, et al. (2008) eHealth trends in Europe 2005-2007: a population-based survey. J Med Internet Res 10, e42.
43. Powell J, Inglis N, Ronnie J, et al. (2011) The characteristics and motivations of online health information seekers: cross-sectional survey and qualitative interview study. J Med Internet Res 13, e20.

44. Feufel MA \& Stahl SF (2012) What do web-use skill differences imply for online health information searches? J Med Internet Res 14, e87.

45. Burns JM, Davenport TA, Durkin LA, et al. (2010) The internet as a setting for mental health service utilisation by young people. Med J Aust 192, S22-S26.

46. Burns JR \& Rapee RM (2006) Adolescent mental health literacy: young people's knowledge of depression and help seeking. J Adolesc 29, 225-239.

47. National Institute of Statistics and Economic Studies (INSEE) (2015) Employed population by sex and socioprofessional categories. http://www.insee.fr/fr/ themes/tableau.asp?reg_id=0\&ref_id=NATnon03173 （accessed January 2015). 